\title{
$P$ wave abnormalities with myocardial infarction: an aid to the diagnosis of left ventricular failure
}

\author{
T. A. HASSELL $\dagger$ \\ M.B., M.R.C.P. \\ Commonwealth Medical Scholar, \\ 1968 and 1969
}

\author{
B. I. HofFBRAND* \\ B.M., M.R.C.P.
}

Resident Assistant Physician

University College Hospital, London, W.C.1

\begin{abstract}
Summary
An investigation during a prospective study of myocardial infarction has confirmed previous observations of $P$ wave changes in association with left ventricular failure. Although an indicator of pre-existing left ventricular disease as well as acute left atrial distension, a negative deflection of $1 \mathrm{~mm}$ or more in the $P$ wave of lead $V_{1}$ should raise strong suspicions about the presence of this serious complication.
\end{abstract}

\section{Introduction}

The early recognition and treatment of left ventricular failure (LVF) has been strongly advocated as a means of reducing the mortality following myocardial infarction (Meltzer, 1968). Clinical and radiological diagnosis of LVF is all too often inadequate, whilst the monitoring of physiological variables, although more precise, is technically demanding.

The increased filling pressure of the failing left ventricle is frequently, if not always, associated with left atrial hypertrophy and/or dilatation. In the first report of $\mathbf{P}$ wave abnormalities in the electrocardiogram (ECG) following myocardial infarction, Master (1933) found that the changes were associated with heart failure and attributed them to left atrial distention. Several groups have since reported $P$ wave changes associated with LVF in both valvular (Wood \& Selzer, 1939) and ischaemic heart disease (Sutnick \& Soloff, 1962; Grossman \& Delman, 1969).

In a prospective study of myocardial infarction at University College Hospital, we investigated the potential value of $P$ wave changes as an aid in the diagnosis of LVF.

* Present address: Queen Elizabeth Hospital, St Michael, Barbados, West Indies.

† Present address: Whittington Hospital, London, N.19, to whom reprint requests should be addressed.

\section{Methods}

All cases of myocardial infarction from 1 January 1969 to 8 July 1969 were seen shortly after admission by one of us (T.A.H.). The diagnosis of acute myocardial infarction was made according to accepted clinical, ECG and biochemical criteria. LVF was diagnosed in the presence of:

1. Acute pulmonary oedema, recognized by standard clinical signs.

2. Chest X-ray evidence of upper lobe venous distension or interstitial oedema.

3. Any two of the following: crepitations at lung bases, development or intensification of gallop rhythm, dyspnoea, elevated jugular venous pressure.

A 15-lead ECG, recorded by Cardiac Department technicians within $24 \mathrm{hr}$ of admission, was examined by both of us without knowledge of the patient's clinical state. A record was made (1) of the contour and maximum amplitude and duration of the standard lead P waves; (2) of the depth and width of the negative deflection of the $P$ wave in praecordial lead $V_{1}\left(P_{\left(v_{1}\right)}\right) ;(3)$ of the presence or absence of diphasic $P$ waves in lead $V_{2}$. Cases without sinus rhythm were excluded.

\section{Results}

A total of eighty-five cases of myocardial infarction was subject to statistical analysis. The age of the patients, of whom fifty-seven were male, ranged from 35 years to 88 years (median 61). LVF occurred in thirty-six patients $(42 \%)$.

The absolute numbers and incidence of specific $P$ wave features in the patients with and without LVF are given in Table 1. The group in failure showed a higher incidence of all $P$ wave abnormalities although only the difference in incidence of large negative deflections in $P_{\left(v_{1}\right)}$ proved statistically significant. As might be expected there was, amongst the patients with LVF a higher incidence of previous heart 
TABLE 1. Incidence of $\mathbf{P}$ wave abnormalities in 85 cases of myocardial infarction with and without left ventricular failure (LVF)

\begin{tabular}{|c|c|c|c|c|}
\hline & LVF & No LVF & $\chi^{2}$ & $P$ \\
\hline $\mathbf{N}$ & 36 & 49 & - & 一 \\
\hline$P\left(v_{1}\right)$ Negative, amplitude $\geqslant 1.0 \mathrm{~mm}$ & $13(36 \%)$ & $3(6 \%)$ & $10 \cdot 33$ & $<0.005$ \\
\hline$P\left(V_{1}\right)$ Negative, duration $\geqslant 0.04 \mathrm{sec}$ & $19(53 \%)$ & $15(31 \%)$ & $3 \cdot 38$ & $<0 \cdot 10$ \\
\hline$P$ duration $\geqslant 0.12 \mathrm{sec}$ and/or notched & $11(31 \%)$ & $13(27 \%)$ & 0.03 & N.S. \\
\hline$P$ amplitude $\geqslant 2.0 \mathrm{~mm}$ and/or peaked & $9(25 \%)$ & $6(12 \%)$ & $1 \cdot 53$ & N.S. \\
\hline Diphasic $\mathbf{P}\left(\mathrm{V}_{2}\right)$ & $17(47 \%)$ & $17(35 \%)$ & 0.90 & N.S. \\
\hline
\end{tabular}

disease and hypertension $(70 \%$ v $35 \% ; P<0.005)$ and a higher hospital mortality $(36 \% \mathrm{v} 10 \% ; P<$ $0 \cdot 01$ ).

\section{Discussion}

The second portion of the $\mathbf{P}$ wave represents electrical depolarization of the left atrium alone (Wenger \& Hofmann-Cudner, 1952; Reynolds, 1953). In normal subjects the amplitude of the terminal portion of $\mathbf{P}_{\left(\mathrm{v}_{1}\right)}$ is less than $-1.0 \mathrm{~mm}$ (Morris et al., 1964). With left atrial dilatation and hypertension, this negative deflection becomes deeper and widened (Dines \& Parkin, 1959), reflecting a posterior rotation of the atrial vector. Morris et al. (1964) found that these changes are a more sensitive indicator of left atrial involvement in valvular heart disease than are the classical standard lead $\mathbf{P}$ wave abnormalities. The findings of Sutnick \& Soloff (1962) and our own show that in ischaemic heart disease in addition, $P$ wave changes in praecordial lead $V_{1}$ rather than in standard leads indicate left atrial distension more reliably.

Sutnick \& Soloff (1962), in patients with LVF due to a variety of causes, observed the $P_{\left(v_{1}\right)}$ changes returning towards normal with disappearance of the failure suggesting that these changes are due to acute left atrial dilatation. With clearing of LVF, deeply negative terminal $\mathbf{P}$ wave deflections in lead $V_{1}$ became normal in two of our cases but in others the ECG abnormalities persisted. It thus appears that the high incidence of abnormal $P$ waves in $V_{1}$ with LVF complicating myocardial infarction is likely to be due to a combination of acute left atrial dilatation and more chronic left atrial involvement due to longstanding left ventricular disease (Arevalo, Spagnuolo
\& Feinstein, 1963). The rarity of atrial infarction and its frequent association with atrial dysrhythmias (Liu, Greenspan \& Piccirillo, 1961) make it unlikely that such an event significantly affected our findings.

\section{Acknowledgment}

Our thanks are due to Dr Arthur Hollman for helpful advice.

\section{References}

Arevalo, A.C., Spagnuolo, M. \& Feinstein, A.R. (1963) A simple electro-cardiographic sign of left ventricular failure. Journal of the American Medical Association, 185, 358.

Dines, D.E. \& Parkin, T.W. (1959) Some observations on $P$ wave morphology in praecordial lead $\mathrm{V} 1$ in patients with elevated left atrial pressure and left atrial enlargement. Proceedings of the Mayo Clinic, 34, 401.

Grossman, J.I. \& Delman, A.J. (1969) Serial P wave changes in acute myocardial infarction. American Heart Journal, 77, 336.

Liu, C.K., Greenspan, G. \& Piccirillo, R.T. (1961) Atrial infarction of the heart. Circulation, 23, 331.

MASTER, A.M. (1933) P wave changes in acute coronary occlusion. American Heart Journal. 8, 462.

Meltzer, L.E. (1968) In Acute Myocardial Infarction (Ed. by D. G. Julian and M. F. Oliver), p. 208, Livingstone, Edinburgh.

MorRis, J.J., Estes, E.H., Whalen, R.E., Thompson, H.K. \& McIntosh, H.D. (1964) $P$ wave analysis in valvular heart disease. Circulation, 29, 292.

REYNOLDS, G. (1953) The atrial electrogram in mitral stenosis. British Heart Journal, 15, 250.

SutNicK, A.I. \& Soloff, L.A. (1962) Posterior rotation of the atrial vector. An electrocardiographic sign of left ventricular failure. Circulation, 26, 913.

Wenger, R. \& Hofmann-Cudner, D. (1952) Observations on the atria of the human heart by direct and semi-direct electrocardiography. Circulation, 5, 870 .

Wood, P. \& Selzer, A. (1939). A new sign of left ventricular failure. British Heart Journal, 1, 81. 